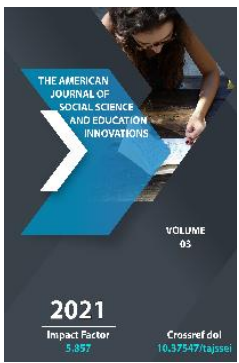

\title{
Mathematics In Physics
}

Yuldashev Laziz Tashpulatovich

Almalyk Branch Of Tashkent State Technical University, Uzbekistan

Toshpulatova Khushnoza Laziz Qizi

Student Of The Faculty Of Physics, National University Of Uzbekistan

Journal Website:

https://theamericanjou

rnals.com/index.php/ta

jssei

Copyright: Original content from this work may be used under the terms of the creative commons attributes 4.0 licence.

\section{ABSTRACT}

This article discusses the major and minor problems in the organization of education and their solutions, the interdisciplinary relationship in the study of physics, in particular, the ideas of mathematics in physics.

\section{KEYWORDS}

Physical quantities, elementary mathematics, test, rating, right triangle, circle diameter, catheter, hypotenuse.

\section{INTRODUCTION}

The process of studying physics requires mastering various natural sciences (mathematics, chemistry, biology, astronomy, geography, ...). The purpose of studying these sciences is to fully imagine, understand, and anticipate the cause and effect of an event in order to analyze natural processes. Only in this way it is possible to solve physical problems quickly, accurately, thoroughly, to approach the process in a reasonable way, to draw the 
right conclusions about what is happening. Below we comment on several articles on interdisciplinary relevance.

\section{LITERATURE REVIEW}

In the literature, the article "Methods of teaching the physical and technological concepts of the process of conversion of solar energy into electricity" analyzes the possibility of forming physical and technological concepts of the process of conversion of solar energy into electricity in physics education. There are also several methodological recommendations on how to teach students on this topic. However, there are uncertainties in the connection of processes that do not belong to certain areas [1].

The co-authored article "Formation of students' skills in solving logical problems in physics" notes that the development of logic in Central Asia had a direct impact on the formation of the worldview of Farobi, Ibn Sina, Ibn Rushd, Beruni and other progressive thinkers. The importance of their use in physics lessons has been shown, given the low use of logical problems in the development of mental and intellectual abilities [2].

The authors of the article "Opportunities to use the integration of natural sciences in the teaching of biomass and biogas production processes" discuss the possibility of teaching biomass, biogas production processes in academic lyceums and professional colleges using science integration in science education.

In addition, using the integration of natural sciences (physics, biology, ecology), a model course technological map was proposed for conducting classes in academic lyceums and professional colleges [3].
From the data explained, it can be understood that it would be expedient to use the integration of disciplines in higher education as well. The article of our colleagues "Interdisciplinary synchronous (vertical) connection in the teaching of biology" analyzes the role and importance of interdisciplinary synchronous connection in the teaching of biology in secondary schools.

There is also a lesson plan on synchronous communication in the teaching of biology. Based on the above considerations, the curriculum of general secondary schools, with a view to linking biology with physics, provides a meaningful analysis of the curricula of both subjects, identifying the links between them, i.e. asynchronous (horizontal) and synchronous (vertical), and the formation of theoretical knowledge, practical skills and competencies of students through the development of environmental problems and tasks, taking into account their psychological characteristics, the application of environmental problems and tasks in the educational process.

Based on this knowledge, problems in physics (especially qualitative problems are easier to solve, conclusions are determined, the quality of the result is improved). The quality of education will be improved if the ideas based on these ideas are applied to universities [4].

\section{MATERIALS AND METHODS}

In the process of learning, however, many quantities have to be measured and calculated. These things cannot be done without mathematics. This article, which is devoted to showing the relationship of physics with other natural sciences, analyzes the literature in this field. Observations show that knowledge of elementary mathematics is sufficient to master the basic principles and concepts of physical processes, only in some cases secondary and 
trigonometric equations are applied, while elements of higher mathematics are almost never applied. It is no secret that the success of students in physics (as well as other natural sciences) depends on the degree to which they have mastered mathematics. This argument requires students to determine their knowledge of mathematics before embarking on a study of physics. There are many ways to determine student knowledge, and in recent years, methods such as testing and rating have also emerged and are widely used. In order to improve the determination of the level of preparation of students in mathematics, for many years, the mistakes typical of high school students, students of primary schools were studied. Efforts in this regard have led to the formation of the proposed unconventional method of investigation. This method is used for high school students (mostly high school students) who are interested in independent study of physics, as well as for students who graduated from high school in previous years. It should be noted that professors and teachers of low-performing secondary schools were established at the initiative of the President to carry out propaganda work in these schools. and work is being done to motivate them. We will get acquainted with the results of the survey conducted in schools 4, 27, 46 of Kuy-Chirchik district of Tashkent region, 6 schools of Akhangaron district, 28 schools of Piskent district. Readers, check which of the following mathematical relationships is incorrect? he was asked.

1. If $\frac{1}{R}=\frac{1}{\mathrm{R} 1}+\frac{1}{R 2}$ then $R=R_{1}+R_{2}$

2. $\frac{A}{B}+\frac{X}{Y}=\frac{A+X}{B-Y}$

3. $(a-B)^{2}=a^{2}-B^{2}$

4. If the diameter of the circle is $10^{-8} \mathrm{~cm}$, then its radius is $10^{-4} \mathrm{~cm}$.

5. The radius of this circle is $5^{-8} \mathrm{~cm}$.
6. In a right-angled triangle, a catheter with an angle of $60^{\circ}$ is equal to $1 \mathrm{~cm}$, then the hypotenuse is equal to $\sqrt{3} \mathrm{~cm}$.

7. $6: \frac{1}{2}=3$

8. $\sqrt{25 a b}=5 a b$

9. $\sqrt{10^{4}}=10^{2}$

10. $\frac{1}{x+2}=\frac{1}{x}+\frac{1}{2}$

11. $\frac{10^{-8}}{10^{-4}}=10^{-10}$

12. Suppose $a$ and $b$ are negative numbers and $\frac{b}{a}$ is greater than one. In that case (a-b) the difference is negative. (All of these mathematical relationships are wrong. After all, it's the sum of the students' mistakes).

Once answers are received from students, they are graded. We consider a completely correct answer (those who say they are all wrong) to be satisfactory, and even if they make one mistake (even those who say one to be correct). Students who understand this will agree. Analysis of the next didactic requirement answers. We are unable to provide a comparative analysis of all the correct and incorrect answers. Let's just focus on questions 4 and 5 . This is wrong. the answers are 20,000 and 512 times larger than the actual answers, respectively. Despite the simplicity of the questions, the number of entrants who have made such big mistakes is considerable, to whom our grandfather $A$. Navoi: "A scientist who learns by asking what he doesn't know. He is a tyrant who does not ask. it is permissible to explain his wisdom. 
The contribution of the story is that the inability of the examined students to complete simple tasks has a special effect on their psyche. As a result, they take a serious approach to learning, work hard, and achieve great things.

Another point: In order to increase the knowledge of students with an unsatisfactory assessment of mathematics, it is very useful for them to use examples of pure mathematics problems, as well as problems of physical content. Here are some examples of issues that are recommended to them:

1. How many times does a wave of green light emit a wavelength of one meter? (The wavelength is taken from the table).

2. Calculate the proton density. (The diameter and mass of the proton are taken from the table).

3. Z. Remove the cube root from six levels of six?

4. What is ten degrees minus one-fifth of it?

5. The number of molecules in $2 \mathrm{~g}$ of hydrogen is equal to the Avagadro constant. What is the mass of one hydrogen atom? (There are 2 atoms in one hydrogen molecule).

6. A $100 \mathrm{~m}$ long piece is visible at a one-degree angle. What is the height of the item? (The guide is one degree - one of 360 of the centre angle of the circle. So the height of the object is one of 360 of the length of the circle with a radius of $100 \mathrm{~m}$ ),

This method of determining students' knowledge was discussed at a methodical meeting of physics and mathematics teachers in the schools where the observations were made. The participants of the meeting agreed on ways to further improve the teaching of physics and mathematics by eliminating the errors inherent in all classes.

\section{CONCLUSION}

In conclusion, in order to master the material in physics, it is necessary not only to study the laws of physics - rules, observations, and processes - but also to have a thorough understanding of all events in the natural sciences. Importantly, mastering other natural sciences without knowing mathematics does not make any sense, because "Mathematics is the king of sciences - but it is the servant of all sciences"!

\section{REFERENCES}

1. Urazalieva, D. A. (2015). Methods of teaching the physical and technological concepts of the process of conversion of solar energy into electricity. Modern education (Uzbekistan), (5).

2. Ishmurodova, G. I., \& Maxmanov, E. B. (2020). Formation of students' solutions to logical problems in physics. Modern education (Uzbekistan), (3 (88)).

3. Aliyorova, N. O., Ismoilov, E. O., \& Kudirov, Sh. Sh. (2015). Possibilities of using the integration of natural sciences in teaching biomass and biogas production processes. Modern education (Uzbekistan), (6).

4. Raxmatullaev, B. A. (2015). Interdisciplinary synchronous (vertical) connection in teaching biology. Modern education (Uzbekistan), (11).

5. Perelman Ya.l. (1992). Do you know physics? Moscow: Nauka.

6. Tashpulatovich, Y. L. (2021). The 
Importance Of Quality Issues In The Teaching Of Physics. The American Journal of Social Science and Education Innovations, 3(05), 104-108.

7. Tulchinsky M.E. (1972). High-quality physics problems in high school. A guide for teachers. Moscow: Education.

8. J. Orir. (1969). Popular physics. "Peace". Moscow.

9. Zikirov, M. C., Qosimova, S. F., \& Qosimov, L. M. (2021). Direction of modern design activities. Asian Journal of Multidimensional Research (AJMR), 10(2), 11-18.

10. Muhiddinovna, B. Z. (2020). Functions and forms of chemical experiment. European science review, (1-2).

11. Djuraeva, D. D., \& Berdiyeva, Z. M. (2016). Cultural heritage as a factor of human development (on the example of Uzbekistan). Ученый XXI века, 23.

12. Berdiyeva, Z. M., \& Niyazov, L. N. (2016). Use of information and communication technologies in teaching the subject of chemistry in higher education institutions. ученый XXI века, (5-2), 26-29. 